\title{
Los nuevos conflictos jurídicos laborales a propósito de la COVID-19(*)
}

\section{The new legal conflicts involving labor aspects regarding the COVID-19}

\author{
Jorge Toyama Miyagusuku(*) \\ Estudio Vinatea \& Toyama Abogados (Lima, Perú) \\ Sofia Yomond Santos ${ }^{(* *)}$ \\ Estudio Vinatea \& Toyama Abogados (Lima, Perú)
}

\begin{abstract}
Resumen: La COVID-19 ha cambiado la forma en la que vivimos y consigo el modo, condiciones y medidas sanitarias en el trabajo. Además de los notables cambios, la pandemia ha generado gran incertidumbre en la sociedad y diversos cuestionamientos sobre su gestión en el ámbito laboral. Precisamente, la COVID-19 ha ocasionado un impacto en la relación laboral, tanto en la modificación de los sistemas de trabajo, como la aparición de nuevos conflictos jurídico laborales, principalmente por el posible contagio de coronavirus en el centro de trabajo o con ocasión de las labores. Los principales conflictos se encuentran relacionados a las materias de indemnización por daños y perjuicios, impugnación de ceses, pago de beneficios sociales, cuestionamientos de medidas de suspensión de labores, entre otros.
\end{abstract}

Palabras claves: COVID-19 - Coronavirus - Relación laboral - Trabajo - Conflictos Procesos laborales - Indemnización por daños y perjuicios - Despido - Derecho laboral

\begin{abstract}
COVID-19 has changed the way we live and with it, the ways, conditions, and sanitary measures at work. In addition to these notable changes, this pandemic has created great uncertainty among the whole society and diverse questionings about its management in the workplace. Precisely, COVID-19 has caused an impact on the labour relationships, both in the modification of work systems, and the appearance of new legal conflicts involving labour aspects, mainly due to the spread of coronavirus in the workplace or on the occasion of the labours carried out by workers. The main conflicts are related to the matters of compensation for damages, challenge of dismissals, payment of social benefits, questioning of measures to suspend the working relationships between employers and employees, among others.
\end{abstract}

Keywords: COVID-19 - Coronavirus - Employment relationship - Work - Conflicts - Labor procedure - Damages - Dismissal - Labor Law

(*) Nota del Editor: este artículo fue recibido el día 12 de octubre de 2020 y su publicación fue aprobada el 13 de noviembre de 2020.

${ }^{* *}$ Abogado por la Pontificia Universidad Católica del Perú (PUCP). Profesor principal de la PUCP, profesor de la Universidad del Pacífico y de la Universidad de Piura. Director de la revista Soluciones Laborales. Miembro extraordinario de la Asociación Civil IUS ET VERITAS. Socio del Estudio Vinatea \& Toyama Abogados. ORCID: https://orcid.org/0000-0002-9034-600X. Correo electrónico: jtoyama@vinateatoyama.com

$\left.{ }^{(* *}\right)$ Abogada por la Universidad Peruana de Ciencias Aplicadas (UPC). Asociada del Estudio Vinatea \& Toyama Abogados. ORCID: https://orcid.org/0000-0002-5569-0614. Correo electrónico: syomond@vinateatoyama.com 
El coronavirus ha mostrado de manera real e imprevisible la situación sanitaria de la sociedad a nivel internacional. Esta nueva realidad, o también llamada nueva normalidad, ha trascendido al derecho laboral; además de su impacto en la salud y estabilidad laboral de los trabajadores, ha demandado la adopción de nuevos estándares de seguridad y sanidad por parte de los empleadores, los cuales deben ser cumplidos con rigurosidad.

Evidentemente, el coronavirus ha causado un gravísimo impacto en la economía y sostenibilidad de las mismas (muchos estiman que el PBI peruano caerá en casi $15 \%$ el 2020 , siendo una de las caídas más altas del mundo): "El nuevo Coronavirus ha encontrado al país con un perfil del trabajo todavía informal, y generará estragos en la expansión económica del presente año. En el mercado de trabajo peruano los primeros signos ya se han empezado a notar" (Revista Actualidad Laboral, 2020).

Precisamente, la coyuntura que atravesamos no solo ha repercutido la economía, sino que también nos ha exigido como sociedad tomar nuevas y drásticas medidas sanitarias, lo que finalmente, también, ha impactado considerablemente en el ámbito laboral, la informalidad laboral, la tasa de desempleo, el incremento del subempleo y no menos importante, en los sistemas de trabajo y la llamada "nueva laboralidad". Aun así, la situación es más compleja, pues actualmente las empresas deben cumplir con las medidas sanitarias en el trabajo así como el ausentismo laboral por los casos positivos y sospechosos, situación que evidentemente encarece los gastos laborales y empeora el panorama global laboral. Por su parte, los trabajadores también se han visto afectados: pérdidas de empleo, suspensiones laborales, retrasos en pago de salarios y hasta liquidaciones de empresas.

Sin perjuicio de que las empresas y los trabajadores se encuentran obligados a cumplir con estrictas medidas sanitarias en el centro de trabajo y en el desarrollo de labores, ello no elimina la posibilidad de un contagio del coronavirus entre los trabajadores, en el centro de trabajo o con ocasión de las labores.

En ese sentido, en el presente artículo abordaremos los temas relacionados a la nueva laboralidad, el impacto de la COVID-19 en el inicio, desarrollo y extinción de la relación laboral, los principales conflictos jurídicos laborales y los juicios laborales que han aparecido a propósito de la COVID-19.

\section{Impacto de la COVID-19 en las relaciones laborales}

La COVID-19 ha generado un sinnúmero de cambios en la forma en la que vivimos y también en las relaciones laborales. Al respecto, la Organización Internacional de Trabajo señaló que:

El Covid-19 tendrá una amplia repercusión en el mercado laboral. Más allá de la inquietud que provoca a corto plazo para la salud de los trabajadores y de sus familias, el virus y la consiguiente crisis económica repercutirán adversamente en el mundo del trabajo en tres aspectos fundamentales, a saber: 1) la cantidad de empleo (tanto en materia de desempleo como de subempleo); 2) la calidad del trabajo (con respecto a los salarios y el acceso a protección social); y 3) los efectos en los grupos específicos más vulnerables frente a las consecuencias adversas en el mercado laboral [énfasis agregado] (OIT, 2020b).

En ese contexto, tal y como la OIT lo ha reconocido, el coronavirus ha impactado considerablemente en las relaciones laborales, principalmente de las siguientes formas: (i) reducción de personal (despidos) y disminución de salarios (en Lima Metropolitana estima el INEI que el sueldo promedio ha caído un mínimo de10\%); (ii) aumento de la informalidad y subempleo; y, (iii) la adaptación de las empresas a la nueva laboralidad y adopción de las medidas obligatorias de sanidad.

\subsection{Considerable aumento de tasa de desempleo}

La reducción de la actividad económica, así como las restricciones a la libertad de tránsito han afectado el mercado laboral, ocasionando efectos negativos en la promoción, contratación y reducción de personal, así como también en los ingresos de los trabajadores. Ello, además, ha dado lugar a la disminución del consumo de bienes y servicios, lo que ha repercutido adversamente en la continuidad de la actividad empresarial y en la capacidad de recuperación económica (OIT, 2020b).

Pues bien, en este contexto, nuestro país atraviesa un incremento notable de la tasa de desempleo. Únicamente en lo que respecta a Lima Metropolitana, en el trimestre de febrero a abril la tasa de empleo disminuyó en un $25 \%$, dejando de trabajar un promedio neto de 1 millón 241 mil 300 personas, mientras que, en el último trimestre de mayo a julio, la tasa de desempleo aumentó en un 16,4 \%, conforme se puede advertir en el gráfico 1.

A nivel nacional, el INEI estima que se han perdido más de 6 millones de empleos en esta pandemia. La tasa de desempleo se ha duplicado y la mayoría de los trabajadores afectados ha cambiado de 


\section{Gráfico 1: Tasa de desempleo}

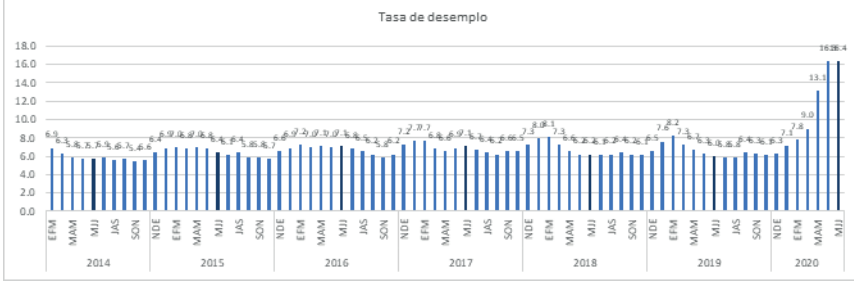

Fuente: INEI (2020)(1)

actividad económica. Una de las cuarentenas más rígidas del mundo ha ocasionado una crisis económica que ha impactado seriamente al mercado de trabajo; sin embargo, ello dependerá de forma considerable de la evolución futura de la pandemia, de la reactivación económica y de las medidas políticas que sean adoptadas (OIT, 2020a).

\subsection{Aumento de tasa de informalidad y subempleo}

La pandemia por la COVID-19 ha repercutido en el crecimiento económico del país, lo cual ha causado efectos negativos en su expresión más directa, en el ámbito laboral y del empleo. Los ingresos de la mayoría de las empresas han disminuido significativamente, situación que las ha llevado a ajustar sus costos e inclusive cerrar sus operaciones ${ }^{(2)}$.

\section{Gráfico 2: PBI - Empleo formal}

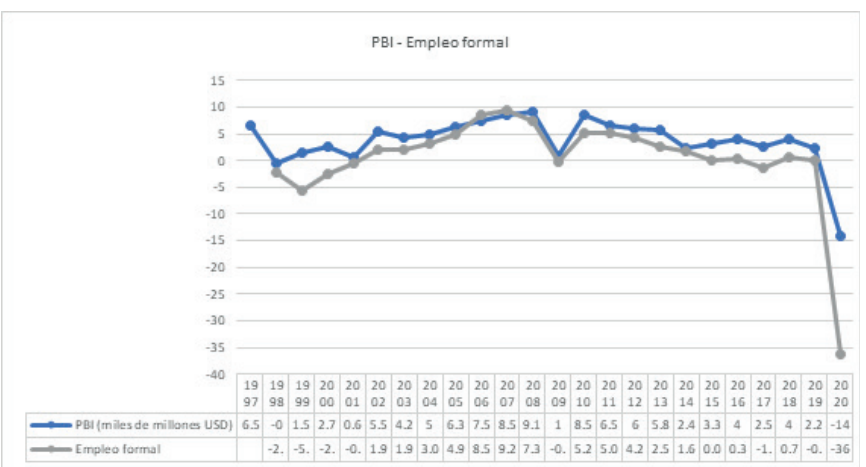

Fuente: BCRP (2019), FMI (2020) y MTPE (2019(3)
Desde el brote pandémico del coronavirus, hemos sido testigos del deterioro del mercado laboral. Lamentablemente, esto también se ha reflejado en la formalidad de las relaciones laborales o contratos de trabajo, cuyo gran problema continúa siendo la elevada tasa de informalidad del empleo: $72.4 \%$ (Revista Actualidad Laboral, 2020).

No obstante, antes del brote epidemiológico de la COVID-19 el Perú ya contaba con una alarmante y elevada tasa de informalidad del empleo. Como consecuencia del coronavirus y la drástica caída del PBI, la tasa de trabajo informal se agudizó, generando una disminución en los ingresos salariales y un aumento del subempleo, situación que ha empezado a notarse y a revertir el avance alcanzado en los últimos años (gráfico 2).

En la actualidad la tasa de informalidad se ha incrementado drásticamente, como consecuencia directa de los efectos económicos de la COVID-19. Se estima que la informalidad se ha incrementado hasta alcanzar casi el $80 \%$ de la economía. Los trabajadores que estaban en la formalidad han migrado al sector informal, un trabajo precario, con menos salario y sin protección social.

\subsection{Nuevos sistemas de trabajo}

Por su parte, las empresas y los trabajadores han tenido que cumplir con las medidas sanitarias decretadas, adaptándose a los nuevos sistemas de trabajo para que la relación laboral sea sostenible, tanto en cuestiones económicas como en exposición de riesgos, situación conocida como la nueva laboralidad. Esta nueva laboralidad se puede resumir principalmente en dos modalidades de trabajo.

(1) Instituto Nacional de Estadística e Informática (2020). Comportamiento de los indicadores de mercado laboral a Nivel Nacional (Informe No. 03). Lima: s/e. Recuperado el 07 de agosto de 2020, de http://m.inei.gob.pe/biblioteca-virtual/boletines/empleo-a-nivelnacional-9721/1/\#lista

(2) Apoyo Consultoría y Servicio de Asesoría Empresarial (2020). Ajuste rápido y doloroso del empleo formal. Reporte Especial (Reporte especial del 8 de abril del 2020).

(3) Banco de Central de Reserva del Perú (2019). Variación porcentual del Producto Bruto Interno 1997-2019. Recuperado el 10 de agosto del 2020, de https://estadisticas.bcrp.gob.pe/estadisticas/series/anuales/resultados/PM04863AA/html

Werner, Alejandro (26 de junio del 2020). FMI revisa "marcadamente a la baja” PBI de Perú en el 2020: -13.9\%. Diario Gestión. Recuperado el 12 de agosto del 2020, en https://gestion.pe/economia/fmi-revisa-sustancialmente-a-la-baja-pbi-de-peru-en-el-2020-14-noticia/?ref=gesr Ministerio de Trabajo y Promoción del Empleo (2019). Variación anual y variación promedio anual del empleo en empresas privadas formales de 10 a más trabajadores por rama de actividad económica, octubre 1998 - diciembre 2019. Recuperado el 10 de agosto del 2020, de http://www2.trabajo.gob.pe/promocion-del-empleo-y-autoempleo/informacion-del-mercado-de-trabajo/estadisticas-de-empleo/ 


\subsubsection{Trabajo remoto}

Es una modalidad de trabajo no presencial y excepcional mientras se encuentre vigente el estado de emergencia sanitaria (Vinatea \& Toyama, 2020). No requiere de acuerdo entre empleador y trabajador y tampoco exige que la empresa compense al trabajador por proporcionar alguna condición para ejecutar el trabajo, salvo pacto entre ambas partes.

Si bien existe un vacío legal al respecto, resulta lógico que en caso el trabajador no cuente con los medios necesarios para la prestación de sus labores (por ejemplo, una computadora), el empleador deberá facilitarlos con la finalidad de asegurar el efectivo cumplimiento de las funciones del trabajador.

Esta modalidad, actualmente, es aplicada por la mayoría de empresas con personal administrativo en atención a su carácter excepcional a propósito del estado de emergencia sanitaria, toda vez que - evidentemente - disminuye la exposición al riesgo de sus trabajadores al contagio de la COVID-19. No obstante, el trabajo remoto limita la exposición al virus, es necesario establecer un adecuado sistema de trabajo que permita la adaptación del personal a los medios tecnológicos, y que, además, se cumplan necesariamente con los estándares ergonómicos.

Las empresas tuvieron que adecuarse de inmediato al trabajo remoto y muchas se han dado con la sorpresa que pueden seguir operando sin mayores dificultades, inclusive en algunos casos hasta mejorando la productividad laboral. El trabajo remoto llegó para quedarse. Las encuestas en las que se preguntan a empresarios y trabajadores sobre la continuidad del trabajo remoto obtienen una mayoritaria respuesta positiva (Alarcón, 2020). En ese sentido, es probable que, incluso superado el estado de emergencia sanitaria, las empresas continúen con esta modalidad de trabajo, por lo menos de manera mixta.

\subsubsection{Trabajo presencial}

En caso de que una empresa deba laborar en forma presencial, deberá cumplir estrictamente con todos los protocolos, medidas sanitarias y su plan para la vigilancia, prevención y control de la COVID-19, con la finalidad de prevenir, vigilar y controlar el contagio de sus trabajadores de coronavirus. Ente las principales medidas, tenemos:

\begin{tabular}{c|l} 
\\
\hline
\end{tabular}

Asimismo, es importante que una empresa, que cuente con trabajadores que presten labores presenciales, verifique: (i) la suscripción de declaración jurada de sus trabajadores, así como la asunción de responsabilidad voluntaria para el caso de los trabajadores que conforman el grupo de riesgo, y, (ii) la integración de la prevención y gestión de COVID-19 en el sistema de gestión de seguridad y salud en el trabajo y contando con la participación de trabajadores.

La crisis sanitaria, además de los efectos negativos ya conocidos, ha ocasionado mayor desigualdad laboral; en la modalidad de trabajo remoto por ejemplo, el hombre ha sido menos impactado que la mujer, pues la tendencia de que la mujer sea quien asuma la mayor parte de los roles filiales y del hogar, lo cual evidentemente dificulta el desempeño en el trabajo desde casa. En el caso de los trabajadores que realizan actividades operativas o administrativas, se han visto más perjudicados en comparación de los trabajadores de dirección, pues han sido cesados, suspendidos o simplemente han estado más expuestos al virus. Del mismo modo, los trabajadores más calificados y de mejores retribuciones han sido menos afectados que aquellos que tienen menor calificación profesional y bajas remuneraciones.

\section{La nueva laboralidad y los conflictos jurídico- laborales}

\subsection{La nueva realidad en el proceso de selección y reclutamiento del personal}

Si bien en medio de la incertidumbre y la posibilidad de un rebrote de la pandemia, los procesos de selección y, por ende, la contratación de personal, han disminuido, cabe preguntarnos ¿cuáles son los nuevos retos o la nueva realidad a la que nos enfrentamos en un proceso de selección y reclutamiento de personal?

El panorama resulta complejo, sobre todo porque en nuestro país aún existe un sector que no cuenta con acceso a la tecnología e internet. Lo cierto es que, quienes tienen acceso a tecnología, se pueden adaptar rápidamente a los nuevos sistemas de

Fuente: Elaboración propia. 
trabajo, pero aquellos que no, se encuentran todavía en proceso de adaptación y búsqueda de nuevas oportunidades laborales.

Pues bien, a propósito de la COVID-19, los empleadores se han visto forzados a realizar una gestión parcial e inclusive totalmente digital en sus procesos de selección (Toyama \& Rodríguez, 2019) y en la relación laboral como tal. Como señala Todolí Signes:

Una de las mayores innovaciones del trabajo en plataformas ha sido su capacidad de producir una nueva forma de organización del trabajo. La tecnología actual (aplicaciones, páginas web, smartphones, algoritmos, entre otros) permite nuevos modelos de negocio y de prestación de servicios que despiertan el interés de los consumidores (2020, p. 281).

Dicha situación ha generado que el proceso de selección y reclutamiento sea más eficiente y célere. Esto, por ejemplo, se hace evidente con los sistemas remotos a través de los cuales un postulante, desde cualquier lugar del mundo, puede resolver pruebas, "asistir" a entrevistas de trabajo o participar en dinámicas grupales (Todolí, 2020).

En efecto, la tecnología ha retado a los empleadores a rediseñar sus procesos, volviéndolos más flexibles, céleres e incluso amigables para quienes cuentan con las herramientas digitales necesarias y se han adaptado correctamente a la nueva laboralidad. Al respecto, también se ha reconocido que, en los procesos de selección digitales, se recoge información de las redes sociales de los postulantes, lo cual incide en su contratación:

Un estudio de Useful Social Media junto con Hootsuite ha verificado que un tercio de las empresas reconocen la práctica de recogida de datos en las redes sociales para decidir la contratación de un trabajador y los fallos judiciales indican su uso para sancionar el trabajador (Reis de Araujo, 2019, p. 178).

Entonces, el proceso de selección digital, aunque resulta ser célere, simple y menos costoso, es ¿infalible? Lo cierto es que, aunque estos nuevos métodos sean eficientes pueden traer consigo consecuencias negativas dentro de un proceso de selección y reclutamiento e incluso afectar los derechos fundamentales de los postulantes.

\subsection{Principales conflictos jurídico laborales causados por} el nuevo proceso de selección y reclutamiento de personal Con la incorporación de nuevas tecnologías como la big data y la inteligencia artificial, el proceso de selección se ha automatizado en función de algoritmos. A partir de los patrones definidos en base a la experiencia digital, es posible que se encubran preferencias por personas de determinada nacionalidad, clase socioeconómica, nivel educativo, estado de salud, entre otros.
En efecto, la detección de supuestos discriminatorios en estos procesos de selección se hace más compleja y difícil, al estar posiblemente encubiertos en decisiones automatizadas y que podrían entenderse inclusive como ajenas a la voluntad del empleador.

Empero, toda persona tiene derecho a la no discriminación y no cabe duda de que dicho deber genérico incluye también a las decisiones automatizadas adoptadas por algoritmos dentro de las organizaciones, lo que ha cambiado con la introducción de estas nuevas tecnologías es que las posibilidades de detección de actos discriminatorios son mucho menores. El nuevo sistema de selección y reclutamiento de personal puede encubrir criterios discriminatorios, situación que podría desencadenar un conflicto jurídico laboral.

Por otro lado, considerando que por disposiciones de rango legal, con la finalidad de prevenir y mitigar la exposición al contagio de la COVID-19 de las personas con condiciones de salud específicas, tales como mayores de 65 años, personas diagnosticadas con hipertensión arterial refractaria, enfermedades cardiovasculares graves, cáncer, diabetes mellitus, asma moderada o grave, enfermedad pulmonar crónica, entre otras, se ha determinado un trato diferenciado para este colectivo que tiene un impacto en la selección y contratación de estas personas. La imposibilidad de trabajo presencial durante la cuarentena sanitaria salvo acuerdo entre las partes (pero que no elimina la responsabilidad por daños y perjuicios del empleador), han reducido las opciones de selección para este grupo de riesgo (Ministerio de Salud, 2020, considerando 7.3 .4$)^{(4)}$.

Es en ese sentido, si la determinación de un trato diferenciado por ley constituye un factor objetivo para tratar diferente y de forma especial a las personas que conforman el grupo de riesgo, entonces ¿es justificable que una empresa en el proceso de selección y reclutamiento de personal considere las condiciones de salud de los postulantes como

(4) Considerando 7.3.4. del Documento Técnico "Lineamientos para la vigilancia, prevención y control de la salud de los trabajadores con riesgo de exposición a COVID-19" aprobado mediante Resolución Ministerial 448-2020-MINSA. 
un factor determinante? La respuesta sería afirmativa.

El hecho de que legalmente se haya establecido un trato distinto de un grupo de personas significa que existe una causa objetiva de diferenciación entre las personas que no conforman el grupo de riesgo y las personas que sí. En cuanto a la selección de personal, resulta válido entonces que se evalúen las condiciones de salud de los postulantes, e incluso su historial médico. Para que sea válido, se deberá considerar: (i) la naturaleza de las labores del puesto para el cual los trabajadores postulan y, (ii) la necesidad de prestar servicios presencialmente.

Así, en la medida de que se necesite personal para un puesto de trabajo que, por la naturaleza de las funciones, requiera de la prestación servicios de forma presencial, una empresa preferirá optar por aquel postulante que no cuente con condiciones de salud que expongan potencialmente su vida y que no se encuentre comprendido en el grupo de riesgo, sin que ello sea interpretado como un acto discriminatorio.

Inclusive, en el supuesto de que una empresa contrate a una persona que se encuentra dentro del grupo de riesgo, ya sea para trabajo presencial o trabajo remoto, deberá cumplir, aún con mayor rigurosidad, con todos los requisitos de ley, protocolos y medidas sanitarias, de manera que no exponga la salud y la vida de dicho trabajador.

Por otro lado, es probable y hasta razonable de que las de personas que tuvieron el virus y fueron sintomáticas, puedan ser preferidas en los procesos de selección y reclutamiento de personal, ya sea para trabajo remoto o presencial, debido a que existen menores probabilidades de que dicha persona vuelva a contagiarse, aminorando los riesgos y peligros por exposición y ausentismo laboral.

Ahora bien, nuestra legislación laboral actualmente prevé los supuestos de discriminación como un supuesto que tiene lugar en el centro de trabajo de forma presencial ante ofertas públicas de trabajo, no regula los casos de discriminación como consecuencia de algoritmos o plataformas digitales, tampoco contempla el supuesto de diferenciación objetiva por la condición de salud de postulante. Lo cierto es que los supuestos expuestos constituyen oportunidades para que la norma sea actualizada y modificada atendiendo a la nueva laboralidad y los conflictos que podrían surgir.

Es evidente que debido a la nueva normalidad que nos toca afrontar, en lo que respecta al ámbito laboral, existen diversos desafíos para la promoción, contratación y reinserción laboral. En buena cuenta, las intenciones del gobierno en materia laboral se han visto rebasadas por la realidad, pero es necesario adecuar la regulación al nuevo entorno digital para limitar al máximo posible las discriminaciones "algorítmicas" que se producen en los procesos de selección.

\subsection{La nueva laboralidad y el im- pacto en desarrollo de la relación laboral}

La pandemia continúa afectando gravemente a la salud pública y causando estragos en la economía y en el sector laboral. No obstante, se han adoptado muchas medidas para contener la propagación del virus, como el distanciamiento físico, las restricciones a la libertad de tránsito, la suspensión de actividades no esenciales, y el confinamiento de ciudades enteras, en el sector laboral ha provocado la adopción de nuevos sistemas de trabajo y la adaptación de los sistemas ya conocidos.

En este nuevo entorno, los empleadores han transitado por un panorama complejo y cambiante, adaptándose y elaborando planes de contingencia para prevenir, controlar y mitigar la propagación del coronavirus en el trabajo. Asimismo, muchas empresas han explorado las posibilidades y beneficios que ofrece el trabajo remoto como una modalidad vigente durante el estado de emergencia sanitaria.

Aun cuando diversas empresas han retomado sus actividades, lo han hecho bajo la modalidad de trabajo remoto, a modo de cumplir las medidas de aislamiento. Asimismo, el optar por la modalidad de trabajo remoto, ha obligado al empleador y trabajador a la capacitación al nuevo sistema de trabajo, al conocimiento, uso y obtención de elementos tecnológicos y herramientas ergonómicas, todo ello con la finalidad de contar con las adecuadas condiciones de trabajo.

Las empresas más impactadas por la pandemia y la cuarentena impuesta por el Estado (no realizan actividades esenciales) han aplicado la modalidad del trabajo remoto para determinadas posiciones pero se han visto en la necesidad de aplicar la medida de suspensión de labores respecto de puestos de trabajo que requieren de presencia física o simplemente ante la inviabilidad de continuar operando y, evidentemente, la imposibilidad de la prestación del servicio de forma virtual, situación que se podría prolongar hasta terminado el estado de emergencia sanitaria. 
Por su parte, las empresas que brindan servicios esenciales y realizan actividades de forma presencial, han ejecutado las medidas sanitarias decretadas destinando un presupuesto para ello, así como afrontando el ausentismo laboral. Sin embargo, lo cierto es que no todas las empresas han tenido la posibilidad de asumir los costos para operar presencialmente, lo cual ha ocasionado diversos conflictos jurídico laborales, tales como el pago a destiempo de beneficios laborales, la suspensión de labores, compensación de gastos, reducción de remuneraciones, entre otros.

En efecto, debido a las drásticas y diversas medidas gubernamentales de restricción sanitaria, se ha generado un panorama de incertidumbre y confusión en lo que respecta a la aplicación de disposiciones y normas laborales. Debido a la dispersa regulación y medidas adoptadas de forma imprevista, confusa y hasta contradictoria, se ha generado diversos cuestionamientos sobre la aplicación de las normas laborales, apareciendo conflictos jurídicos en las relaciones laborales.

Atendiendo a ello, los conflictos jurídico labores que han aparecido a propósito de la nueva laboralidad, pueden ser divididos en atención a la modalidad de prestación de servicios o situación del trabajador, conforme al siguiente cuadro:

\section{Tabla 1}

\begin{tabular}{|c|c|c|}
\hline Tipo & Supuesto & Conflictos laborales \\
\hline \multirow{8}{*}{$\begin{array}{l}\text { Trabajador } \\
\text { activo }\end{array}$} & \multirow{3}{*}{$\begin{array}{l}\text { 1. Trabajador: } \\
\text { modalidad } \\
\text { presencial }\end{array}$} & $\begin{array}{l}\text { - Indemnización por daños y perjuicios - Enferme- } \\
\text { dad profesional COVID-19 }\end{array}$ \\
\hline & & $\begin{array}{l}\text { - Indemnización por daños y perjuicios por falle- } \\
\text { cimiento o exposición al peligro por COVID-19 }\end{array}$ \\
\hline & & - Ausencias por temores a la enfermedad \\
\hline & \multirow{3}{*}{$\begin{array}{l}\text { 2. Trabajador: } \\
\text { modalidad } \\
\text { remota }\end{array}$} & - Indemnización por daños y perjuicios - Ergonomía \\
\hline & & - Pago de beneficios sociales - Horas extras \\
\hline & & - Compensación de gastos \\
\hline & $\begin{array}{l}\text { 3. Trabajador } \\
\text { de grupo } \\
\text { de riesgo }\end{array}$ & $\begin{array}{l}\text { - Indemnización por daños y perjuicios por expo- } \\
\text { sición al peligro } \\
\text { - Compensación de los períodos de licencia com- } \\
\text { pensable. }\end{array}$ \\
\hline & $\begin{array}{l}\text { 4. Trabajador } \\
\text { suspendido }\end{array}$ & $\begin{array}{l}\text { - Impugnación de suspensión perfecta de labores } \\
\text { y pago de beneficios sociales }\end{array}$ \\
\hline
\end{tabular}

Fuente: Elaboración propia

En ese sentido, en los siguientes acápites explicaremos los principales aspectos que se deben tener en cuenta en los conflictos jurídico laborales que han aparecido a propósito de la nueva laboralidad, nuevos sistemas de trabajo y repercusiones del coronavirus en la relación laboral.

\subsection{Principales conflictos jurídico laborales en el desarrollo de la relación laboral}

\subsubsection{Trabajador en modalidad de trabajo presencial}

Principalmente quienes laboran de forma presencial, en particular los trabajadores de la salud, se encuentran altamente expuestos a riesgos sanitarios y económicos. Es por ello que los principales conflictos jurídico laborales son los relacionados a las materias indemnizatorias y resarcitorias por coronavirus o exposición al peligro.

A) Indemnización por daños y perjuicios por enfermedad profesional de COVID-19

La COVID-19 ha sido reconocida mediante la Ley 31025 como enfermedad profesional para los servidores de salud, modificando consigo la Ley de Modernización de la Seguridad Social en Salud.

Este conflicto podría tener lugar cuando un trabajador de la salud que labora con pacientes con la enfermedad sea diagnosticado de coronavirus, situación que habilita al trabajador para solicitar una indemnización por daños y perjuicios por el padecimiento de COVID-19. Para ello se deberá analizar si la incapacidad del servidor ocasionada por el coronavirus es de carácter temporal o permanente, toda vez que dicho factor incidirá en el otorgamiento de la indemnización.

En ese sentido, el trabajador de salud podría solicitar la indemnización por daños y perjuicios como consecuencia de padecer COVID-19, supuesto en el que resulta necesario se analice: la exposición al riesgo por parte del trabajador, si el trabajador cumplió con las medidas sanitarias facilitadas por su empleador y/o si la empresa cumplió con las medidas sanitarias obligatorias. En otras palabras, se deberá analizar la concurrencia de los elementos de la responsabilidad civil: conducta antijurídica, daño, nexo causal y factor de atribución.

B) Indemnización por daños y perjuicios por fallecimiento COVID-19

Si bien la regla general es que la COVID-19 es una enfermedad profesional de los servidores 
de salud, también podría generarse una controversia en caso un trabajador ordinario adquiera la enfermedad de coronavirus en el centro de trabajo o con ocasión de sus labores.

Este conflicto podría presentarse cuando trabajador adquiere COVID-19 en el centro de trabajo o con ocasión de sus labores, y dicha enfermedad ocasiona la muerte del mismo o deja secuelas en el trabajador. Como consecuencia de ello, los sucesores del trabajador se encontrarían habilitados para solicitar al ex empleador el pago de una indemnización por daños y perjuicios.

Sin embargo, una interrogante que inmediatamente surge es ¿Cómo se prueba que el contagio de COVID-19 fue en el centro de trabajo o con ocasión de las labores? Es complicado determinar, dónde y cuándo se adquirió la enfermedad, y la respuesta resulta aún más compleja cuando hablamos de una persona que ha fallecido.

Sobre el particular, es evidente que el estándar de la prueba que se requerirá de iniciarse un conflicto de dicha naturaleza será aún más alto que el regular. En ese caso, se deberá analizar el cumplimiento de las medidas sanitarias por parte del empleador, la conducta del trabajador y otras situaciones en las que el trabajador pueda haber contraído el virus. El principal elemento jurídico de la responsabilidad civil que se deberá analizar sería el nexo causal entre la enfermedad y/o la muerte y la prestación de labores, además de los elementos mencionados preliminarmente.

C) Indemnización por daños y perjuicios por exposición al peligro

Podríamos encontrarnos ante un conflicto jurídico laboral por exposición al peligro cuando el empleador no cumpla con las medidas sanitarias obligatorias, o en el caso de que exija a los trabajadores la prestación de labores presenciales sin que haya necesidad de ello.

Al respecto, es importante precisar que, debido a la regulación cambiante y profusa, cabe la posibilidad de que los empleadores omitan entregar equipos de protección personal obligatorios a sus trabajadores o se debate sobre la calidad y características de los mismos (por ejemplo, si el trabajador solicita una mascarilla quirúrgica cuando el empleador considera una de tela como suficiente). Muestra de que ello, es que, en su oportunidad, se determinó que los guantes eran de uso obligatorio para quienes prestaban labores presenciales, sin embargo, luego ello dicha disposición se dejó sin efecto.

Asimismo, respecto a las pruebas serológicas $\mathrm{y} / \mathrm{o}$ moleculares, en un principio se estableció su obligatoriedad, luego la medida quedó sin efecto. Inclusive, aun cuando diversas empresas vienen implementando dicha medida preventiva y de control, actualmente no existe base normativa que determine la obligación ni la periodicidad de dicha medida.
Es por ello que, debido a que no existe un panorama claro sobre la regulación y las medidas de obligatorio cumplimiento que deben adoptar las empresas, es común que los trabajadores puedan encontrarse expuestos al peligro, situación que podría desencadenar un conflicto. Nuevamente, al tratarse de un conflicto de naturaleza indemnizatoria, se deben analizar la concurrencia de los elementos de la responsabilidad civil que hemos visto precedentemente.

\subsubsection{Trabajador en modalidad de trabajo remoto}

En el caso de los trabajadores que realizan labores en la modalidad de trabajo remoto, se pueden advertir conflictos jurídico laborales en el supuesto de que no cuenten con condiciones de trabajo adecuadas (ergonomía) o en caso de que hayan incurrido en gastos para contar con las medidas necesarias y trabajar desde sus domicilios.

A) Indemnización por daños y perjuicios por la falta de entrega de condiciones ergonómicas

Si bien el trabajo remoto no tiene regulación específica, surgen dudas en lo que respecta a la habilitación de condiciones de trabajo y la dotación de herramientas de trabajo ergonómicas, toda vez que no existe expresa disposición de que el empleador se encuentre obligado a brindarlas para la prestación de labores de forma remota.

Si bien, en lo que respecta a la dotación de los medios tecnológicos, se dispuso que cuando empleador y trabajador lo convengan, pueden acordar la compensación de los gastos adicionales derivados del uso de los medios o mecanismos, no existe disposición sobre las condiciones ergonómicas con las que el trabajador debe contar en la prestación de labores remota, tales como escritorio, silla, computadora, entre otros.

En definitiva, al no existir una disposición expresa, durante la vigencia del estado de emergencia sanitaria, y por ende la aplicación de la modalidad de trabajo remoto, existen altas probabilidades de que en muchos casos no se hayan otorgado todas las herramientas ergonómicas, lo cual, finalmente, podría provocarel padecimiento de una enfermedad profesional afín. 
En este tipo de conflictos se deberá analizar si el empleador dispuso y aplicó medidas paliativas, como pausas activas, subvención o facilidades de compra de sillas ergonómicas, envío de computadoras o laptops a los domicilios, entre otros factores, que podrían atenuar o enervar el otorgamiento de una indemnización por condiciones ergonómicas. Sin embargo, la falta de condiciones ergonómicas no debe entenderse como la causa directa del padecimiento de una enfermedad profesional, para ello deberán considerarse otros factores importantes.

En este caso se deberá analizar: (i) si el trabajador contó con herramientas ergonómicas, (ii) si el empleador aplicó medidas paliativas para prevenir cualquier daño derivado de las labores (como pausas activas), (iii) si las labores justifican la exposición del trabajador ante una enfermedad profesional y, (iii) el padecimiento de una enfermedad profesional. En este tipo de conflictos, resulta imprescindible analizar concretamente, además de los demás elementos de la responsabilidad civil, el daño, el cual podría consistir en el padecimiento de una enfermedad profesional.

\section{B) Pago de horas extras}

En lo que respecta al pago de beneficios sociales, podría iniciarse un conflicto jurídico laboral por el pago de horas extras como consecuencia del trabajo en modalidad remota, toda vez que mediante los Decretos de Urgencia 026-2020 y 029-2020, no se ha especificado si existe obligatoriedad por parte del empleador para establecer un horario de trabajo, resultando difícil realizar una fiscalización del tiempo de labor efectiva y, por ende, el cálculo del trabajo en sobretiempo u horas extras.

Al respecto, la Autoridad Nacional del Servicio Civil, ha señalado mediante el Informe Técnico 001013-2020-SERVIRGPGSC de fecha de junio del 2020, que en el sector público "[n]o resulta posible que el servidor que se encuentre en la modalidad de trabajo genere horas extras, al no encontrarse sujeto a un horario".

Sin embargo, en este tipo de supuestos, es necesario analizar cada caso en concreto, ya que es un caso excepcional, no regulado y distinto al trabajo presencial. Sobre todo, considerando el horario laboral de cada trabajador y la forma de la fiscalización del trabajo efectivo y trabajo en sobretiempo.

Ante la falta de regulación de este beneficio laboral en el trabajo remoto, se podría generar un conflicto laboral, en el que es importante apreciar: (i) si al trabajador se le asignó un horario de trabajo fijo, (ii) los mecanismos o medios de control de labores efectiva, (iii) si el trabajador ha laborado en sobretiempo, (iv) la duración del trabajo en sobretiempo.

\section{C) Compensación de gastos}

Conforme hemos señalado preliminarmente, mediante Decreto Supremo 010-2020-TR, se ha determinado que las partes, empleador y trabajador, pueden acordar la compensación de los gastos derivados de la obtención y acceso a los medios o mecanismos tecnológicos necesarios para la prestación de servicios.

Sin embargo, ¿Qué sucede cuando no obra acuerdo de por medio y el trabajador incurre en gastos para la obtención de medios tecnológicos necesarios para la prestación de sus labores? En efecto, esta situación podría provocar el inicio de un conflicto jurídico, en el cual es esencial, aunque complejo, determinar cuándo un gasto es necesario para la obtención del mecanismo tecnológico y la relevancia de dicho mecanismo para la prestación de las labores.

Pues bien, en este caso, es imprescindible analizar: (i) si existe acuerdo entre empleador y trabajador para la compensación de gastos, (ii) si la compensación de gastos corresponde a medios con los que ya contaba el trabajador antes de la pandemia, (iii) los gastos incurridos para la obtención de los medios tecnológicos, (iv) la necesidad del medio tecnológico para la prestación del servicio o la relación entre sí, y, adicionalmente (v) la situación económica del trabajador.

\subsubsection{Trabajador de grupo de riesgo}

Los trabajadores que conforman el grupo de riesgo por la COVID-19, también podrían encontrarse inmersos en conflictos jurídicos laborales, atendiendo a que legalmente se ha establecido un trato diferenciado en atención a su especial condición de salud. Hablamos de una eventual indemnización por daños y perjuicios por exposición al peligro.

Podría presentarse un conflicto jurídico laboral cuando trabajadores que conforman el grupo de riesgo se encuentren expuestos al riesgo de contraer COVID-19 al haber acordado con el empleador un trabajo presencial o, evidentemente, si tienen el virus y alegan haberse contagiado en la empresa. En este caso, pueden surgir conflictos porque el empleador no otorga el equipo de protección personal necesario o no toma las medidas sanitarias obligatorias.

Ambos supuestos constituyen conflictos jurídico laborales; sin embargo, como ya hemos señalado, ante la solicitud de una indemnización por daños y perjuicios, es necesario que se analice la concurrencia de los elementos de la responsabilidad civil: el hecho antijurídico, el incumplimiento de 
un dispositivo de rango legal o norma sanitaria, el daño, la exposición al riesgo y las consecuencias de ello, el nexo causal entre la relación laboral y el daño, y el factor de atribución.

\subsubsection{Trabajador suspendido}

En ese punto, abordaremos los conflictos jurídico laborales que se suscitan en el marco de la aplicación de una suspensión perfecta de labores y pagos de beneficios sociales derivados.

A) Impugnación de suspensión perfecta de labores

La suspensión perfecta de labores, debidamente aprobada por la autoridad administrativa de trabajo, podrá hacerse efectiva mientras nos encontremos en estado de emergencia sanitaria, lo cual evidentemente propicia un conflicto jurídico, toda vez que los trabajadores afectados con la medida no percibirán remuneraciones hasta que el estado de emergencia sanitaria sea superado o cuando la empresa reinicie operaciones, lo que ocurra primero.

Así, los trabajadores afectados con la medida o sus representantes podrían solicitar se deje sin efecto la resolución que aprueba la suspensión perfecta de labores. Del otro lado, las empresas pueden cuestionar ante la autoridad laboral si no se aprueba el pedido de suspensión perfecta de labores.

Para resolver estos conflictos se deberá analizar si, para el otorgamiento de la medida de suspensión de labores, la autoridad verificó la concurrencia de todos los requisitos, como, por ejemplo:

- Comunicación a los trabajadores de la medida.

- Hasta donde resulte posible, la adopción de medidas alternativas o paliativas que busquen mantener el vínculo laboral y la percepción de remuneraciones del trabajador.

- Imposibilidad de aplicar trabajo remoto o licencia con goce de haber compensable por naturaleza de las actividades o por afectación económica relevante.

- Presentar dentro de plazo la solicitud de la medida ante la autoridad administrativa de trabajo.

Estamos ante conflictos jurídicos donde se aprecia si la empresa se encontraba ante una causal que impidiera sus operaciones a tal punto que debe aprobarse una suspensión sin goce de remuneraciones de los trabajadores comprendidos en la medida. Los conflictos son resueltos por la autoridad administrativa de trabajo y, en caso de que una de las partes no esté de acuerdo, quedará la vía de la impugnación judicial, esto es, un proceso judicial contra la resolución que aprueba o rechaza la suspensión de labores.

Cabe indicar que en estos procesos administrativos y judiciales han participado sindicatos en reuniones previas para evitar una suspensión de labores, así como dentro del proceso administrativo y también judicial. La presencia del sindicato usualmente genera mayores escenarios de cuestionamiento administrativo y judicial pero también ha servido en ocasiones para arribar acuerdos colectivos para evitar una suspensión o extinción de los contratos de trabajo, por ejemplo suscribiendo convenios de reducción de sueldos, disminución de la jornada, suspensión de beneficios convencionales, etc.

\section{B) Pago de beneficios sociales}

Por su parte, podría iniciarse un conflicto jurídico laboral en cualquier modalidad de prestación de servicios o situación del trabajador, cuando la empresa no realice el pago correspondiente a los beneficios sociales de los trabajadores. Este incumplimiento se produce ante una paralización o suspensión intempestiva de operaciones sin seguir los procedimientos establecidos. Se trata de empresas que, ante los efectos de la pandemia y cuarentena, optaron por cerrar sus actividades. Muchas de ellas han quebrado y, en estos casos, las posibilidades de pago de beneficios sociales son remotas.

\subsection{El coronavirus y el impacto en la extinción de las relaciones laborales}

Como es evidente y conforme hemos expuesto preliminarmente, nuestro país atraviesa un considerable e inminente aumento de la tasa de desempleo, tal es así que, en el trimestre de mayo a julio, la tasa de desempleo aumentó en un 16,4 \%. Dicha situación ha sido provocada por la pandemia de la COVID-19 y sus efectos directos en la economía y el empleo.

Atendiendo a la crisis económica agudizada por el coronavirus, diversas pequeñas y grandes empresas, con gran incertidumbre y la fundada preocupación por la continuidad de sus actividades productivas, han optado por alternativas para la reducción del personal y la extinción de contratos de trabajo.

En esta línea, muchas empresas han llegado a acuerdos con sus trabajadores para reducción de sueldos o término de los contratos de trabajo; sin embargo, gran número de ceses se han producido pese a la negativa de los trabajadores de negociar su salida de la empresa, ceses en forma unilateral y sin causa justa. Adicionalmente 
a ello, se han realizado ceses colectivos, en atención a la naturaleza del contexto económico y sanitario por el brote pandémico de coronavirus. Como sostiene Salinas:

La pandemia de COVID-19 y las medidas implementadas para enfrentarla evidentemente constituyen un caso fortuito y fuerza (...). Pero la magnitud y configuración de sus elementos constitutivos resulta insuficiente para justificar la terminación de relaciones laborales y solamente alcanza para sustentar una suspensión (interrupción) de las mismas (...).

[L]a terminación de la relación laboral debido a un caso fortuito o de fuerza mayor, aunque fuera jurídicamente procedente, a la luz de una interpretación sistemática de nuestro ordenamiento jurídico laboral, así como de los precedentes aplicativos a nivel normativo, jurisprudencial, comparado y doctrinal, sí obliga al empleador a indemnizar al trabajador de una manera consistente con el despido intempestivo (Salinas, 2020).

Conforme se puede advertir, no obstante, el brote epidemiológico por la COVID-19 constituye un supuesto de caso fortuito y fuerza mayor, el cual habilita al empleador a extinguir la relación laboral, si no se observa el procedimiento legal (léase un proceso de cese por causas objetivas), se debe indemnizar al trabajador que sea afectado por la extinción de su contrato de trabajo de forma unilateral cuando no medie causa justa; inclusive, salvo casos de trabajadores que ocupan posiciones de confianza, el trabajador afectado podría demandar su reposición al centro de trabajo.

En concreto, ¿qué sucede en los casos en los que las empresas extinguieron las relaciones labores con sus trabajadores de forma unilateral? En esos supuestos, se deberá analizar la naturaleza del cese, en función al motivo señalado por el empleador que motiva el cese, el contexto por el cual el empleador cesó al trabajador e inclusive las condiciones o beneficios otorgados al cese del trabajador.

\section{Tabla 2}

\begin{tabular}{|c|c|c|}
\hline Tіро & Supuesto & Sub tipología \\
\hline \multirow{8}{*}{$\begin{array}{l}\text { Trabajador } \\
\text { cesado }\end{array}$} & \multirow{2}{*}{$\begin{array}{l}\text { 1. Trabajador que } \\
\text { negoció su cese }\end{array}$} & - Impugnación de cese: despido fraudulento \\
\hline & & - Indemnización por daños y perjuicios \\
\hline & \multirow{3}{*}{$\begin{array}{l}\text { 2. Trabajador cesa- } \\
\text { do unilateralmen- } \\
\text { te }\end{array}$} & $\begin{array}{l}\text { - Impugnación de cese: despido fraudulento, } \\
\text { incausado o arbitrario }\end{array}$ \\
\hline & & - Pago de beneficios sociales \\
\hline & & - Indemnización por daños y perjuicios \\
\hline & \multirow{3}{*}{$\begin{array}{l}\text { 3. Impugnación de } \\
\text { procedimiento } \\
\text { administrativo }\end{array}$} & $\begin{array}{l}\text { - Ceses colectivos: caso fortuito, reestructu- } \\
\text { ración, fuerza mayor o motivos económicos }\end{array}$ \\
\hline & & $\begin{array}{l}\text { - Ceses colectivos: reestructuración patrimo- } \\
\text { nial }\end{array}$ \\
\hline & & $\begin{array}{l}\text { - Ceses colectivos: liquidación o resolución } \\
\text { de empresa }\end{array}$ \\
\hline
\end{tabular}

Fuente: Elaboración propia
Sin embargo, además de los conflictos laborales derivados de los ceses injustificados o unilaterales, existen conflictos en los que los trabajadores se encontrarán habilitados para solicitar una indemnización de índole laboral o civil, por los daños derivados del cese, o su reposición al centro de trabajo. En ese sentido, analizaremos los principales conflictos jurídico laborales iniciados como consecuencia del cese o extinción del vínculo laboral. Estos casos se pueden agrupar en tres tipos (Tabla 2).

\subsection{Principales conflictos jurídico laborales en la extinción de la relación laboral}

\subsubsection{Trabajador que negoció su cese}

En la coyuntura que atravesamos, no hemos sido ajenos a las repercusiones del coronavirus en la economía nacional y mundial. Ello evidentemente, también ha propiciado la paralización de labores, pérdida de ingresos, e incluso el cierre de diversas empresas. Producto de ello, un buen número de empresas han optado por negociar la salida de sus trabajadores.

A) Impugnación de cese: reposición por despido fraudulento

Un conflicto jurídico laboral que podría surgir como consecuencia de la suscripción de un acuerdo o negociación entre empleador y trabajador es la impugnación judicial que este último realiza respecto a su cese, solicitando su reposición en su centro de trabajo señalando haber sido despedido bajo un vicio de voluntad (error, engaño, violencia, etc.).

En la coyuntura, es probable que gran parte de los despidos realizados hayan sido unilaterales y no respondan a una causa justificada; asimismo, en el supuesto de que existiera un acuerdo o negociación entre empleador y trabajador, es recurrente que este último invoque un supuesto de coacción para la suscripción del acuerdo, o desconocimiento del mismo, aduciendo haber sido despedido de hecho.

Así, en este tipo de casos, se deberá analizar: (i) la acreditación de un vicio de la voluntad en la suscripción del acuerdo, (ii) la participación del extrabajador en la 
negociación, (iii) la suscripción del acuerdo y los términos, (iv) pago de una indemnización por el cese y/o pago de suma graciosa compensable con ocasión del cese y, (v) si el trabajador cobró las sumas pagadas por el empleador.

B) Indemnización por daños y perjuicios derivados del cese

Podría iniciarse un conflicto jurídico laboral, consistente en la indemnización por daños y perjuicios derivados del cese del trabajador, en la medida de que actualmente se discute si negociar la salida de un trabajador durante la pandemia constituye como un hecho antijurídico.

Lo cierto es que, en atención a la teoría civilista, en caso de que el acuerdo adolezca de vicios de voluntad de las partes, se puede alegar la nulidad. Sin embargo, si convalidó el acto (negociación libre y voluntaria), entonces, el acuerdo se habría perfeccionado y por tanto surtiría efectos entre ambas partes, empleador y trabajador.

No obstante ello, si un trabajador se considera habilitado para solicitar una indemnización por daños y perjuicios, mínimamente se deberá analizar: (i) si el trabajador incurrió en un vicio de voluntad (fue coaccionado o timado para la suscripción del acuerdo), (ii) si ambas partes participaron en la negociación y acuerdo de condiciones, (iii) la convalidación del acuerdo y/o el pago y cobro de sumas -beneficios laborales o suma graciosa- con ocasión de su cese.

\subsubsection{Trabajador cesado unilateralmente}

A) Impugnación de cese: arbitrario, fraudulento, incausado o nulo

Es probable que gran parte de los conflictos jurídico laborales que se han iniciado sea como consecuencia de despidos unilaterales, los cuales podrían agruparse en los siguientes supuestos:

a) Despido fraudulento o arbitrario: En el caso de que se haya producido un despido unilateralmente, con vicio de la voluntad del trabajador, o sin observar un debido procedimiento, el trabajador podría solicitar su reposición o una indemnización. Estos tipos de despidos es muy común actualmente, sobre todo porque la producción e ingresos de diversos sectores se ha visto perjudicado, y la única medida inmediata tomada por diversas empresas, han sido los ceses unilaterales, quienes inclusive han optado comunicar el despido mediante plataformas digitales como zoom o Microsoft Teams o incluso electrónicamente.

Sin embargo, también cabe la posibilidad de que debido a la adopción de las dos modalidades de trabajo (remota o presencialmente), se hayan realizado despidos por la comisión de faltas graves o el ineficiente desempeño de trabajadores. Por ejemplo, en el caso de que un trabajador haya sido convocado para retomar labores presenciales y este no asista aduciendo exposición al riesgo, el empleador evidentemente podría sancionar su desacato con una sanción drástica como el despido. Por otro lado, en caso de que un trabajador se encuentre laborando en la modalidad de trabajo remoto y tenga un desempeño deficiente de sus labores, el empleador podría optar por el cese justificado del trabajador.

b) Despido incausado: En el caso de que se haya producido un despido unilateralmente y sin causa justa que sustente el despido, podría iniciarse un conflicto jurídico laboral en el cual el trabajador, también podría solicitar la reposición a su centro de trabajo.

Por ejemplo, puede darse el caso de que un trabajador que se encuentra laborando bajo un contrato a plazo determinado, pero que constantemente y de forma automática su empleador ha venido renovando sus contratos, de forma intempestiva sea liquidado, por la simple razón de que su contrato de trabajo habría vencido. En este caso, el trabajador podría invocar que correspondía que su contrato de trabajo sea renovado nuevamente o que no tenía una causa temporal y alegar una desnaturalización debiendo ser tratado como trabajador contratado a plazo indeterminado.

c) Despido nulo: Ahora bien, de acuerdo a la coyuntura y a las particularidades de la nueva laboralidad, podemos encontrar despidos que se han realizado por motivos de discriminación, ya sea por casos sospechosos o confirmados de COVID-19, por trabajadores que conforman el grupo de riesgo y que al no poder laborar física ni remotamente, no pueden continuar en la empresa, así como también casos de despidos de dirigentes, representantes sindicales o trabajadores sindicalizados que hayan iniciado reclamos ante la autoridad administrativa de trabajo, por incumplimiento de medidas sanitarias por ejemplo.

Así, si un trabajador solicita la nulidad de su despido, se debe analizar, según sea el caso: (i) la condición subjetiva del 
trabajador (sindicalizado, enfermo de covid-19, etc.), (ii) un despido sin justificación, una causa razonable de término de la relación laboral alegada por el empleador; y, (iii) la relación causal entre la condición del trabajador y el motivo alegado por el trabajador, como puede ser la fecha de presentación del juicio de daños y perjuicios por haber sido contagiado de covid-19 y el cese incausado; o la cercanía entre la fecha de diagnóstico y circunstancias del contagio del extrabajador, si fue contagio en el centro de trabajo o a consecuencia de sus labores, y el día del cese injustificado.

B) Indemnización por daños y perjuicios

En el supuesto de un cese unilateral sin justificación, podríamos encontrarnos ante un conflicto jurídico laboral cuando un trabajador solicita el pago de una indemnización por daños y perjuicios, como consecuencia de su cese.

En este caso, se deberá analizar si el hecho primigenio, es decir el cese, fue consentido o si no fue cuestionado por el trabajador. Asimismo, se deberá verificar si el trabajador cuestionó judicialmente su despido y si acumuló a su pretensión de cuestionamiento del cese un pedido indemnizatorio, aunque también es posible que el petitorio indemnizatorio se realice en otro proceso posterior.

Sin perjuicio de ello, en este tipo de conflictos, resulta de todos modos imprescindible, analizar la presencia de los elementos de la responsabilidad civil ya mencionados: el hecho antijuridico, el daño, el nexo causal y el factor de atribución.

C) Ceses colectivos: caso fortuito, reestructuración, fuerza mayor o motivos económicos

Respecto al cese colectivo, conviene recordar que este se encuentra regulado como una causa justa de extinción del vínculo laboral y que además requiere de aprobación por la autoridad administrativa de trabajo, el mismo que se encuentra regulado por los incisos a) y b) del artículo 46 del Decreto Supremo 003-97-TR.

Si bien ha existido un debate sobre la consideración de la pandemia y sus efectos económicos como causa de caso fortuito fuerza mayor, al respecto Saco Barrios ha señalado que:

Sí es posible -en el Perú- la extinción o término de la relación o contrato de trabajo por causas de "fuerza mayor" o "hechos fortuitos"; siempre que aquella o estos sean de una gravedad tal que acarree la desaparición total o parcial del centro de trabajo (Saco Barrios, 2020).

Por un lado, aun cuando la autoridad administrativa de trabajo haya aprobado la solicitud de cese colectivo, los trabajadores afectados con la medida o sus representantes podrán impugnar la resolución administrativa que aprueba la medida, en el supuesto que consideren que la autoridad de trabajo no analizó la concurrencia de los requisitos para su aprobación o en caso se hayan vulnerado los principios del procedimiento administrativo.
Entonces cabe la pregunta ¿Qué sucede si la impugnación del cese colectivo es amparada? ¿El procedimiento administrativo se declara nulo e inicia nuevamente? O ¿Los trabajadores afectados con la medida podrían solicitar su reposición provisional? Dependerá mucho de los alcances de la sentencia judicial, si se anula la resolución evidentemente se requerirá de un nuevo pronunciamiento administrativo; si se rechaza el cese colectivo, los trabajadores deberían retornar a sus labores ordinarias.

Por otro lado, en caso de que la autoridad administrativa de trabajo deniegue la solicitud de cese colectivo por las causales mencionadas, la empresa podría impugnar judicialmente el procedimiento administrativo en el cual se rechazó su solicitud. En este caso, si se le da la razón en vía judicial a la empresa, los contratos de trabajo se extinguirían por una resolución judicial.

D) Ceses colectivos: reestructuración patrimonial de empresa

Respecto a la reestructuración de empresa, conviene recordar que este supuesto se encuentra regulado como una causa justa de extinción del vínculo laboral, el mismo que se encuentra regulado por artículos 46 y 49 del Decreto Supremo 003-97-TR.

Asimismo, en junio del año en curso, se publicó el Decreto Supremo 012-2020-PCM, mediante el cual se aprueba el Reglamento del Decreto Legislativo 1511, que crea el Procedimiento Acelerado de Refinanciación Concursal ("PARC"), el cual se tramita ante INDECOPI.

Ahora bien, podría ocurrir que los trabajadores o sus representantes, consideren que la medida de cese los ha afectado, o que en el PARC no se han respetado los principios del derecho concursal o del debido procedimiento y que, por tanto, impugnen o cuestionen judicialmente la resolución emitida por el INDECOPI mediante la cual admite el acogimiento de la empresa al PARC.

Los procesos de reestructuración patrimonial buscan suspender los adeudos de las empresas en favor de su continuidad. En estos casos, los conflictos se relacionan con la exigibilidad de pago oportuno de los beneficios sociales, en un concurso de 
acreedores del empleador. En este tipo de procesos no se discuten los conflictos de reposición, solo el reconocimiento de beneficios sociales. Usualmente los créditos laborales no tienen influencia material en los procesos dado que, en la masa concursal, el valor de "lo laboral" es bajo. Prácticamente los créditos laborales se pagan en función de lo que señale quienes controlan la junta de acreedores.

E) Ceses colectivos: liquidación y disolución de empresa

Respecto a la liquidación o disolución de empresa, conviene recordar que este supuesto se encuentra regulado como una causa justa de extinción del vínculo laboral, el mismo que también se encuentra regulado por artículos 46 y 49 del Decreto Supremo 003-97-TR.

Entre las principales causas para solicitar la liquidación, se encuentran el vencimiento del plazo de una organización (un consorcio, por ejemplo), no haber alcanzado los objetivos planeados, junta general sin actividad, pérdidas que reduzcan el patrimonio a menos de la tercera parte del capital pagado, acuerdo de la junta de acreedores, entre otros.

Sin embargo, en este caso los trabajadores o sus representantes encuentran una limitación a su derecho a cuestionar judicialmente dicho procedimiento, pues aun cuando consideren haber sido afectados con dicho procedimiento, su ex empleador y su personería jurídica se encontrará extinguida. Solamente se puede discutir los beneficios sociales dado que la extinción del contrato de trabajo, derivada de la disolución de la empresa, no puede ser materia de controversia judicial.

\section{Procesos contenciosos administrativos iniciados por la COVID-19}

Como hemos expuesto en el punto anterior, a propósito de la nueva laboralidad y las medidas que se han adoptado en el sector laboral, actualmente se están resolviendo conflictos jurídico laborales. Asimismo, no escapa a la realidad que, como consecuencia de diversos procedimientos administrativos de diferente naturaleza, también se han iniciado procesos contenciosos administrativos.

En efecto, las principales materias sobre las cuales versan dichos procesos son: impugnación de procedimientos de suspensión perfecta de labores e impugnación de sanciones por incumplimiento de normas sanitarias impuestas por Sunafil, los cuales resumiremos en los siguientes acápites:

\subsection{Impugnación de denegatoria de solicitud de suspensión perfecta de labores:}

Si bien es cierto, el coronavirus nos obligó a tomar medidas imprevistas, ello también incidió en la regulación y organización en diversos sectores del país, en este caso el sector laboral.
Desde el inicio de la cuarentena se emitieron diversas medidas con la finalidad de reducir el impacto tanto en empresas y en trabajadores, una de estas fue la suspensión perfecta de labores.

Así, en lo que respecta a la suspensión perfecta de labores, en un principio, tanto el procedimiento y los canales establecidos para solicitar la aplicación de dicha medida, no lograron tutelar todos los principios y derechos que rigen un procedimiento administrativo, dado que la plataforma habilitada y el sistema del Ministerio de Trabajo además de modificar constantemente los formularios e información requerida, en atención a los nuevos dispositivos normativos que se emitían, también colapsó, debido a que múltiples empresas buscaron acceder a la medida. Sin embargo, dichos impases fueron subsanados con el transcurrir del tiempo.

En atención a ello, las empresas o administrados han iniciado procesos contenciosos administrativos contra el MTPE, alegando como principales fundamentos fácticos: i) la modificación constante de información requerida para registrar la solicitud, ii) las averías de la plataforma que no permitían el correcto registro o adecuación de la solicitud, y, iii) la falta de motivación o contradicción en las resoluciones que denegaban las solicitudes de suspensión perfecta de labores.

De otro lado, debido a la emisión de diversas normas profusas y cambiantes, así como el cambio de autoridades, se propició una incorrecta e inclusive indebida interpretación y aplicación de las normas al momento de calificar y resolver las solicitudes de los administrados, lo cual es materia de conocimiento actualmente en sede judicial.

\subsection{Impugnación de sanciones por incumplimiento de normas sanitarias Conforme hemos señalado preliminarmente, debido a la regulación cambiante y profusa, así como encontrarnos ante una nueva regulación, se han generado u sinnúmero}


de fiscalizaciones de la SUNAFIL. En ese sentido, producto de las fiscalizaciones e inspecciones llevadas a cabo por la autoridad administrativa de trabajo, se han sancionado a diversas empresas.

Por su parte, cabe hacer referencia a que las medidas de sanidad decretadas han variado constantemente o existen contradicciones entre las normas generales y los protocolos sectoriales. Tal es así que en un principio era exigible el uso de determinados equipos de protección o la adopción de determinadas medidas de prevención y control del coronavirus, nos referimos a los guantes y pruebas moleculares o serológicas; sin embargo, posteriormente las disposiciones fueron dejadas sin efecto. Dicha situación, ha propiciado que los administrados incurran en faltas administrativas, y como consecuencia de ello, impugnen las multas interpuestas por la SUNAFIL judicialmente.

Por último, cabe recordar que además de los procesos contenciosos administrativos que se han iniciado por las denegatorias de medidas de suspensión perfecta de labores y por las multas en materia de seguridad y salud en el trabajo, conforme hemos señalado, también se han iniciado procesos judiciales contra los procedimientos de ceses colectivos, por caso fortuito, fuerza mayor, motivos económicos, reestructuración empresarial y liquidación o disolución de empresa, los cuales actualmente están siendo conocidos por los jueces laborales.

\section{Reflexiones finales}

El coronavirus ha llegado para quedarse y formar parte de la nueva laboralidad, por ello, la asesoría y capacitación técnica especializada, así como la aplicación de medidas sanitarias preventivas no debe menguar en el transcurso del tiempo. Es indispensable que continuemos haciéndole frente y limitando la exposición al contagio de la COVID-19.

En efecto, el impacto del coronavirus en las relaciones laborales, desde el inicio hasta su fin y la dispersa regulación y medidas adoptadas de forma imprevista, han generado un panorama de incertidumbre y confusión en lo que respecta a la aplicación de disposiciones y normas laborales. Las diversas interpretaciones sobre la aplicación de las normas laborales han ocasionado conflictos jurídicos en las relaciones laborales, siendo necesario que cada caso en concreto sea analizado y resuelto de forma congruente y objetiva, teniendo en cuenta la coyuntura y la situación por la cual atraviesa trabajador y empleador.
Del mismo modo, los conflictos jurídicos y procesos laborales que se han iniciado deben ser gestionados y resueltos de una forma eficiente y adecuada, atendiendo, también, a las nuevas reglas tecnológicas. Así, puede considerarse a la solución de conflictos a través de medios alternativos como una alternativa eficiente, la cual deberá evaluarse dependiendo cada caso en concreto.

Por su parte, es necesario que se continúe reforzando las instituciones gubernamentales y administrativas, quienes además deben: (i) tramitar y resolver los conflictos a nivel administrativo y judicial enteramente de forma virtual, (ii) contar con soporte técnico y especializado (por ejemplo, la participación de epidemiólogos), precisamente para la emisión de pronunciamientos debidamente motivados y conforme a ley y, (iii) buscar resolver los vacíos jurídicos que actualmente existen por la regulación del coronavirus y las medidas dispuestas para su tratamiento en las relaciones laborales.

En conclusión, es innegable que el coronavirus continuará trascendiendo en nuestra vida cotidiana y en las relaciones laborales, situación que se traducirá en conflictos jurídicos y reclamos laborales, pero para que dichos conflictos puedan ser resueltos adecuadamente deben acompañarse de una correcta gestión y análisis técnico y especializado en la materia objeto de la controversia.

\section{Referencias bibliográficas}

Alarcón, Magaly (2020, 21 de julio). Trabajo remoto: veni, vidi, ¿vinci? Vinatea \& Toyama. Recuperado el 11 de agosto del 2020, de https://www.vinateatoyama. com/blog/opinion/trabajo-remoto-veni-vidi-vincihome-office-vinatea-toyama-peru/

Apoyo Consultoría y Servicio de Asesoría Empresarial (2020, 8 de abril). Ajuste rápido y doloroso del empleo formal. Reporte Especial.

Banco de Central de Reserva del Perú (2019). Variación porcentual del Producto Bruto Interno 
1997-2019. Recuperado el 10 de agosto del 2020, de https://estadisticas.bcrp.gob.pe/estadisticas/ series/anuales/resultados/PM04863AA/html

Instituto Nacional de Estadística e Informática (2020). Comportamiento de los indicadores de mercado laboral a Nivel Nacional (Informe No. 03). Recuperado el 07 de agosto de 2020, de http://m. inei.gob.pe/biblioteca-virtual/boletines/empleo-anivel-nacional-9721/1/\#lista

Ministerio de Salud (2020). Resolución Ministerial 448-2020-MINSA. Documento Técnico Lineamientos para la vigilancia, prevención y control de la salud de los trabajadores con riesgo de exposición a COVID-19. Diario Oficial EI Peruano.

Ministerio de Trabajo y Promoción del Empleo (2019). Variación anual y variación promedio anual del empleo en empresas privadas formales de 10 a más trabajadores por rama de actividad económica, octubre 1998 - diciembre 2019. Recuperado el 10 de agosto del 2020, de http://www2.trabajo.gob.pe/ promocion-del-empleo-y-autoempleo/informaciondel-mercado-de-trabajo/estadisticas-de-empleo/

Organización Internacional de Trabajo (2020a). EI COVID-19 causa pérdidas devastadoras de empleos y horas de trabajo. https://www. ilo.org/global/about-the-ilo/newsroom/news/ WCMS 740920/lang--es/index.htm

Organización Internacional del Trabajo (2020b). El COVID-19 y el mundo del trabajo: Repercusiones y respuestas. https://www.ilo.org/global/about-the-ilo/WCMS_739158/ lang--es/index.htm

Saco Barrios, R. (2020). PERÚ: La estabilidad en el empleo en el contexto de la pandemia. Revista jurídica del trabajo, 2, 56-72

Reis de Araujo, Adriane (2019). El poder de control empresarial en la Web 2.0 y la dignidad del trabajador: el uso laboral de los dispositivos móviles y entornos colaborativos. Editorial Bomarzo.

Revista Actualidad Laboral (2020). Efectos laborales de la pandemia por la COVID-19 en el Perú. Incertidumbre y desafíos. Recuperado el 5 de agosto del 2020, de https://actualidadlaboral.com/efectoslaborales-de-la-pandemia-por-la-covid-19-en-el-peru/

Salinas, Pablo. (2020). ¿La pandemia de Covid-19 es caso fortuito o fuerza mayor que justifique terminar legítimamente el contrato individual de trabajo en Ecuador? Revista jurídica del trabajo, 2, 82-91

Todolí, Adrian (2020). Las plataformas digitales y la ampliación del concepto de trabajador: jurisprudencia española y la nueva ley de california (AB5). Revista jurídica del trabajo, 1, 286-288.

Toyama, J. \& Rodríguez, A. (2019). Algoritmos laborales: big data e inteligencia artificial. Revista THEMIS, 75, 255-266.

Vinatea \& Toyama (2020). Conoce las diferencias entre teletrabajo, trabajo remoto y trabajo a domicilio. Recuperado el 10 de agosto del 2020, de https://www.vinateatoyama.com/blog/actualidad/conoce-lasdiferencias-entre-teletrabajo-trabajo-remoto-y-trabajo-a-domicilioperu-vinatea-toyama-jorge/

Werner, A. (2020, 26 de junio). FMI revisa "marcadamente a la baja" PBI de Perú en el 2020: -13.9\%. Diario Gestión. Recuperado el 12 de agosto del 2020, en https://gestion.pe/economia/fmi-revisa-sustancialmentea-la-baja-pbi-de-peru-en-el-2020-14-noticia/?ref=gesr 